\title{
КОНСТРУИРОВАНИЕ ИНТЕГРАЛЬНЫХ ПОКАЗАТЕЛЕЙ КОЛИЧЕСТВЕННЫХ ПРИЗНАКОВ С ПОМОЩЬЮ ОДНОМЕРНЫХ И МНОГОМЕРНЫХ МЕТОДОВ МАТЕМАТИЧЕСКОЙ СТАТИСТИКИ
}

\author{
М. Ю. Антомонов, Е. В. Волощук \\ ГУ «Институт гигиены и медицинской экологии им. А.Н. Марзеева НАМН Украины»
}

The single-and multi-dimensional mathematical statistic methods apply at all stages the integral indicator calculation. Batdimensional techniques can be used for pre-processing and analysis of data for more efficient use of multivariate methods.

Актуальность разработки методов построения интегральных характеристик обусловлена отсутствием определенной математической модели, которая была бы одинаково эффективной для расчета интегральных характеристик здоровья на разных уровнях организации (как на индивидуальном, так и на популяционном) и на основе разных показателей: антропометрических, функционального состояния, адаптационных возможностей организма; рождаемости, заболеваемости, смертности, инвалидности и т.п.

Особенность существующих моделей состоит в том, что они разработаны преимущественно для решения узкого круга задач, и часто их вид зависит от типа обрабатываемых данных. С помощью же информационных технологий становится возможным разработка подходов к расчету унифицированных оценок здоровья, элементами которых могут быть данные, имеющие разную значимость, вариабельность и размерность.

Основными задачами при формировании интегрального показателя являются следующие: определение информативности показателей с последующим сокращением их размерности; приведение показателей к единой шкале измерения с учетом их влияния на исследуемый объект (положительное/отрицательное); расчет весовых коэффициентов показателей; выбор математической модели для расчета интегрального показателя; верификация полученного результата.

Для решения перечисленных задач можно воспользоваться методами одномерной и многомерной математической статистики (табл. 1).

Таблица 1. Применение одно- и многомерных методов математической статистики при расчете интегрального показателя

\begin{tabular}{|c|c|c|}
\hline $\begin{array}{c}\text { Этап расчета интегрального } \\
\text { показателя }\end{array}$ & Критерий / метод & Применение \\
\hline \multicolumn{3}{|l|}{$\begin{array}{l}\text { Формирование перечня } \\
\text { показателей }\end{array}$} \\
\hline \multirow[t]{4}{*}{$\begin{array}{l}\text { Уменьшение размерности } \\
\text { показателей }\end{array}$} & $\begin{array}{l}\text { дисперсия } \\
\text { ассиметрия }\end{array}$ & определение выбросов данных \\
\hline & эксцесс коэффициент вариации & определение типа распределения данных \\
\hline & мода & определение однородности данных \\
\hline & $\begin{array}{l}\text { факторный анализ, } \\
\text { дискриминантный анализ, } \\
\text { кластерный анализ } \\
\end{array}$ & $\begin{array}{l}\text { группировка показателей; } \\
\text { определение показателей с тесными } \\
\text { взаимосвязями }\end{array}$ \\
\hline $\begin{array}{l}\text { Расчет безразмерных } \\
\text { эквивалентов }\end{array}$ & среднее значение / медиана & $\begin{array}{l}\text { определение нормы количественных / } \\
\text { качественных показателей }\end{array}$ \\
\hline Нормирование показателей & вариационная статистика & $\begin{array}{l}\text { приведение значений показателей в } \\
\text { диапазон измерения }[0,1]\end{array}$ \\
\hline $\begin{array}{l}\text { Определение весовых } \\
\text { коэффициентов показателей }\end{array}$ & $\begin{array}{l}\text { факторный, регрессионный } \\
\text { анализ }\end{array}$ & $\begin{array}{l}\text { нахождение значений факторных } \\
\text { загрузок и } \beta \text {-коэффициентов }\end{array}$ \\
\hline $\begin{array}{l}\text { Выбор математической } \\
\text { формулы }\end{array}$ & кластерный анализ (метрики) & $\begin{array}{l}\text { расчет интегрального показателя близос- } \\
\text { ти исследуемого объекта к эталону }\end{array}$ \\
\hline $\begin{array}{l}\text { Верификация интегрального } \\
\text { показателя }\end{array}$ & $\begin{array}{l}\text { среднеквадратическое } \\
\text { отклонение, коэффициент } \\
\text { корреляции }\end{array}$ & $\begin{array}{l}\text { определение точности и качества } \\
\text { интегрального показателя, тесноты связи } \\
\text { с экспериментальными значениями }\end{array}$ \\
\hline Принятие решений & $\begin{array}{l}\text { дискриминантный анализ, } \\
\text { нейронные сети }\end{array}$ & классификация, прогноз \\
\hline
\end{tabular}

(C) М. Ю. Антомонов, Е. В. Волощук 
Применение одно- и многомерных методов математической статистики позволяет учитывать специфику даных при расчете интегральных показателей экологических, гигиеничеких и медицинских объектов и систем. При этом одномерные методы могут быть использованы в качестве основы (на первичных етапах расчета интегрального показате- ля) для остальных случаев размерности расчетных данных. Определенную ценность для определения состояния биологических объектов представляют метрики кластерного анализа, которые при расчете интегральных показателей позволяют учитывать «норму» - наиболее важное понятие в биологи и медицине. 